\title{
The Challenge of the Future as Viewed by a Range Research Worker ${ }^{1}$
}

KENNETH W. PARKER

Director, Range and Wildlife Habitat Research, Forest Service, U.S. Department of Agriculture, Washington, D.C.

It is a privilege and a pleasure to speak at this annual meeting of our Society and to explore the challenges of the future that we face together. To begin - as we think about and examine range problems in need of research, all of us must widen our horizons. With much of our land, whether it is forested range with several competing uses or open grasslands now used exclusively by domestic livestock, we are at the crossroads as to the continuance of any single use. I believe this is so because of changing times and rapidly increasing demands on all lands for many uses.

Our horizons in research must combine range and wildlife habitat for they have much in common, particularly as we study ecological and physiological responses from grazing use, often with identical methods and techniques of vegetation measurement. However, I hasten to add that managing a range for domestic livestock is a good deal different than management for big game, and often we have to consider both in the management of the same area.

Use and management of publicly owned lands is going to be a case of give and take, depending largely on land suitability and group pressure demands of people, tempered by economics. On privately owned lands the same factors are important, but

1 Presented at the symposium on "How We May Meet the Challenge of the Future" during the Seventeenth Annual Meeting, American Society of Range Management, Wichita, Kansas, February 10-14, 1964. the most economical use usually becomes the governing one. Hence, I can see a real challenge in the future for increased emphasis on research on how to best harmonize water, livestock, timber, wildlife and recreation uses.

\section{Historical Development of Grazing in the United States}

Patrick Henry once said: "I know of no way of judging the future but by the past." So let us take a brief look at the historical development of grazing in the United States and the events leading up to the need for range research.

Prior to the advent of domestic livestock in this country, the only grazing animals were game, principally deer, elk, antelope and the tremendous herds of bison on the Great Plains. Over 400 years ago and possibly less than 150 miles from this meeting hall in Wichita, Coronado and his expedition from Mexico are reported to have entered southwestern Kansas. This, in the year 1540 , represents the first entry of domestic livestock into the Western United States. The remarks of Castenada, historian of the expedition, are of historical interest and although possibly exaggerated, are indicative of conditions at that time:

"Who would believe that 1,000 horses and 500 cows and more than 5,000 rams and ewes and more than 1,500 friendly Indians and servants in traveling over these plains would leave no more trace than if nothing had been there - nothing -."

Soon after the Coronado expedition permanent introduction of livestock by Spanish missionaries followed rapidly in California and the Southwest, but elsewhere in the West, the development of a livestock industry did not take place until some 300 years later.

Then, following the Civil War, came a period of rapid development and settlement. Construction of the transcontinental railroads made it possible to market fresh western-grown beef in the east. The cessation of Indian wars, the elimination of the bison by 1883, liberal English capital, and the great wave of homesteading, all contributed to a sharp buildup in cattle numbers to a peak in 1886. In the sheep industry development was extremely rapid after 1880 .

About this time (1874) a highly significant invention was made - barbed wire - which made homesteading possible, and restricted the range available to the stockman. It also made better range management feasible. However, the development of the modern windmill allowed continued expansion of the livestock industry, by opening up formerly unwatered range. But soon thereafter came an end to our grazing land frontiers.

Then came trouble-the western range was overstocked. In the terrible winter of 1886,4 out of 5 animals died over wide expanses of the Great Plains, and in the same year starvation from severe drought in the Southwest caused death losses of 25 to 50 percent. Less than 10 years after these disasters and subsequent similar events, stockmen were making requests to Congress for assistance on such problems as: How to increase range forage by seeding and how to eradicate invading undersirable and often poisonous plants. In a few years a more urgent need for knowledge on which to base sound management was expressed by public forest land managers.

In $1898, \$ 15,000$ was appropri- 
ated to the Bureau of Plant Industry "for grass and forage plant investigations." Thus, by the turn of the century formalized range research was on its way.

\section{History of Range Research}

I am not going to dwell on the history of range research since 1900 -but I do want to highlight its beginnings, mention a few important contributions that I think outstanding, and consider some of the challenges of the future.

Range research furnishes the scientific basis for the intelligent management of rangelands used for grazing. It is an American innovation arising from the early observations of explorers, military leaders, and missionaries on native vegetation and from the exploratory surveys and investigations at the turn of the century of both Federal and State agricultural agencies. This early effort, although primarily concerned with botanical work, did recognize grazing problems and the need for research. Since that time range research has expanded considerably, so that it now encompasses many skills and fields of knowledge. Physiology, botany, ecology, agronomy, soils, genetics, animal husbandry and nutrition, economics, and chemistry all supply background information for range and wildlife habitat management.

Range research, as is true with other agricultural research, is rapidly changing, and to be most effective requires teamwork both of scientists of varying disciplines and of Federal, State, and private institutions. In the Federal Government responsibility lies mainly with the Agricultural Research Service and the Forest Service in the Department of Agriculture. In the States it is conducted almost solely by the State agricultural experiment stations attached to the land- grant colleges. Many private individuals and groups are cooperating.

In the past, applied research, sometimes guided by fundamental studies and sometimes merely by intuition, has accomplished much. Some good management systems were developed, helpful guides for utilization were established, and effective artificial revegetation practices were devised. But much remains to be done.

The crossing of new horizons is going to require better equipped laboratories, greenhouses and other facilities for undertaking a larger amount of basic research, knowledge from which is essential to guide both applied research and management.

\section{Importance of The Range Resource}

In understanding the need for range research, we first have to recognize the importance of the range resource. Grazing is the largest single use of land in the 48 States. Grazing lands cover half the Nation's land area and about a third is in commercial forest or woodland. These lands furnish forage for over $1 / 2$ our beef cattle and $3 / 4$ of our sheep for an average of at least 6 months of the year. We can ill afford to let these lands be idle or inadequately managed.

Much of our range area is of high recreational value and provides a home for wildlife, including over 10 million big-game animals. This is no small item. More and more ranchers are recognizing game as an additional crop on their lands from which they can realize cash returns from leasing or permitting hunting privileges. Similarly, more and more timberland owners, particularly in the South, are realizing benefits from both livestock and game.

But this vast resource is estimated to be producing only half its potential. A comprehensive national range resource review is needed-and needed now -for land use planning and directing emphasis in research programs. The future demand for livestock products in this country requires a close look into the need for improving those resources essential to meet this demand. Our per capita consumption of red meat today is over 170 pounds (97 pounds of which is beef) as compared to an average of 127 pounds per person in the late 1930's, and there are some 50 million more of us here today. If present trends continue, projections indicate we will have another 50 million people by 1980. Undoubtedly demands for red meat will continue to increase as our standards of living continue to improve.

Our challenges come from many directions - biological, social, and economic. Perhaps I should also add-political. Each of us must recognize and shoulder his share of responsibility.

\section{Progress in Range Research}

Range research includes investigations into the entire environmental complex of native grazing lands. It particularly requires an understanding of plant and animal requirements for growth and yield.

In a field to which so many disciplines have contributed, it is possible to review only a spectrum of past progress, as a means of pointing out some of the challenges ahead. In listing some of these accomplishments, I bear in mind that much progress has come about through trial-anderror research combined with range managers' experiences, and some of these have been bitter lessons. Also, at risk of criticism for important omissions, I will mention names of a few scientists (now mostly retired) who I think have made outstanding contributions. 


\section{Management of Range} Vegetation

The most practical means of improving and maintaining both native and seeded range productivity is through proper management. A notable contribution was early recognition of the need to adjust the degree and season of use to the growth requirements of range forage plants. As early as 1899, Jared Smith recommended deferred-rotation grazing for native ranges in Texas. He was to be upheld later by the work of A. W. Sampson in Oregon and Utah and Herbert C. Hanson in Colorado.

A better understanding of the need for periodic rest for recovery of closely grazed ranges and a rational degree of use came with E. C. McCarty's physiological research in the late 1920 's on carbohydrate storage as influenced by grazing and climate. This, of course, was followed by the utilization standards research of R. S. Campbell and co-workers.

I have mentioned deferredrotation grazing. I must emphasize that it has many variations. There are still other systems, and there is certainly no universal agreement as to the best system of grazing use. Perhaps there cannot be in view of the wide variations in climate, vegetation, soil, and often the need to meet requirements of other land uses, but I think we are in essential agreement on fundamentals. Whatever the management system may be, it should provide a method of harvesting forage with optimum animal production and with a minimum injury to vegetation and soils.

I should also mention Dayton's work on range plant evaluation; that of Pammel, Marsh and Clawson on poisonous plants; the early work of Thornber, Wooten, Griffiths and later workers on semiarid ranges in overcoming low production of livestock and reducing death losses during drought; the development of the open herding and bedding out principles for sheep by Jardine, Fleming and others; a better understanding of overcoming damage by livestock to western coniferous timber through studies carried on by Cooperrider and other workers. I would be remiss not to mention the name of W. R. Chapline and his many years of service and influence in the development of a nationwide program of range research in the Forest Service. All of this work led to better management of our ranges which had fallen to a low ebb in condition and productivity in the period 1920-1935. But persistent educational programs by State and Federal agencies were required to put findings into practice.

Research in plant ecology has been an important part of range research almost from the time of its beginnings, being brought sharply into focus by A. W. Sampson, Frederick E. Clements, H. C. Hanson, and others. Their work on plant succession and plant indicators laid the basis for work by M. W. Talbot and by Lincoln Ellison (Figure 1). Note- worthy was the research on the Great Plains by Weaver and his students, including the late Dr. Albertson of Ft. Hays, Kansas. All of this ecological research has led to our present-day concepts of range condition standards and development of criteria for judging trend, as so well expressed by E. J. Dyksterhuis.

What lies ahead? We must have more knowledge of inherent characteristics, growth requirements, patterns of change, and environmental interrelations of range plants. Of particular importance is the determination of effects of herbage removal, fire, soil compaction, temperature and moisture fluctuations, competition among plant species, and of range pests such as rodents, insects, and diseases. We need to know more precisely the role of plant litter and what is needed to meet soil fertility and watershed requirements. Unless this fundamental information is systematically obtained by physiological and ecological studies, we will continue to have gaps in our knowledge that prevent the development of optimum sys-

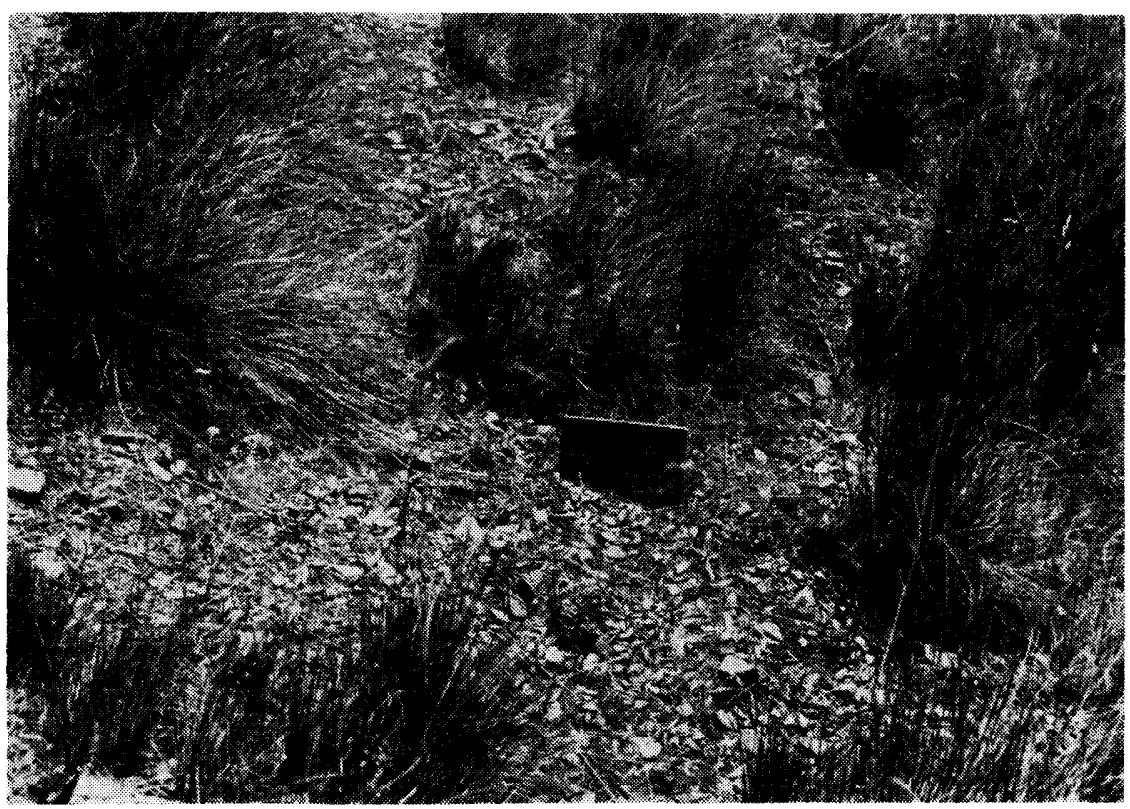

FIGURE 1. A stand reduced by selective grazing almost entirely to one rather unpalatable grass. Absence of young and middle-aged plants emphasizes the very unsatisfactory condition indicated by bare soil and trampling displacement. 
tems of range management. The era of exploratory studies aimed to tell us what happens is rapidly merging into an era of studies aimed to tell us why a given result is obtained.

The facets of range problems are becoming more and more varied. Although we have made much progress, it seems paradoxical that when we seemingly find the solution to one problem, we discover new and sometimes greater problems needing attention. Also, while it is true the grazing animal still and probably will remain the cheapest means of harvesting native forage, this use is becoming inexorably intermeshed with other demands on the land. Certainly, accelerated research is needed on coordination of grazing, timber, wildlife, and watershed values.

The complexity of range problems is increasing-as in the use of herbicides, pesticides and more recently the concern over radioactive fallout. If you think this is merely an ominous threat, I refer you to an article that appeared last September (13th) in Time Magazine, describing the presence of radioactive fallout in

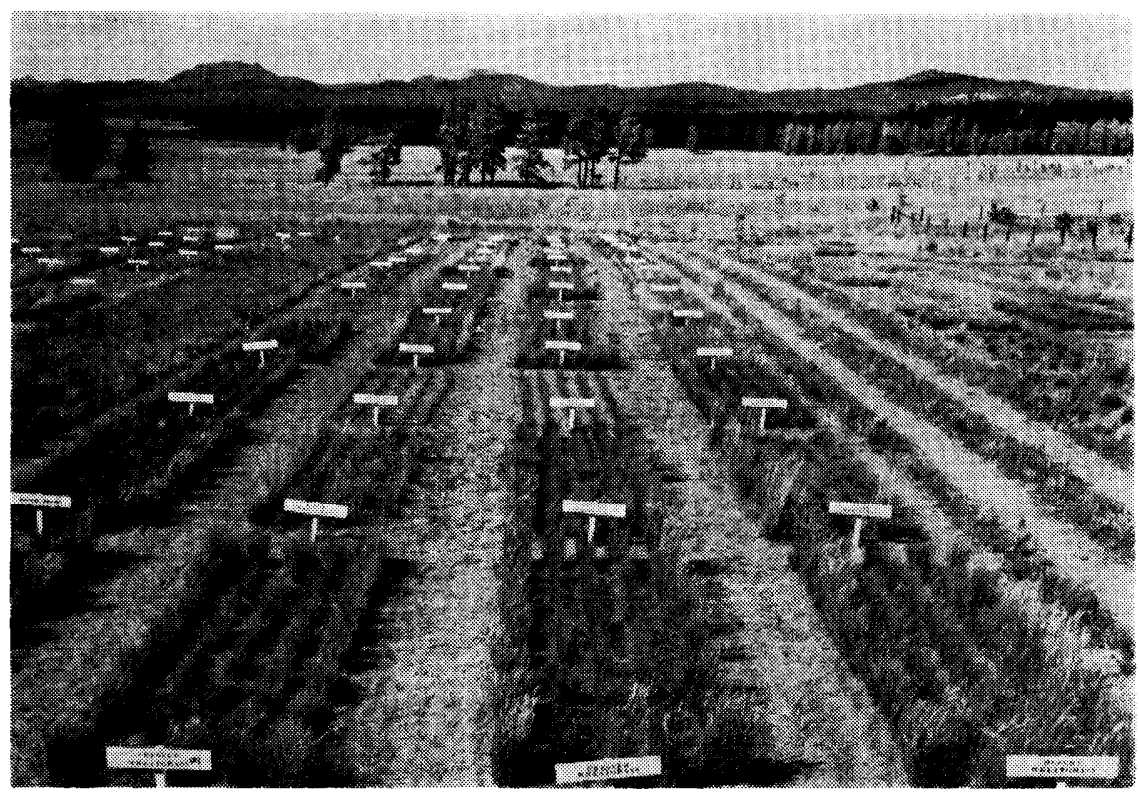

Figure 2. Nursery plots of grasses and legumes at the Manitou Experimental Range, Colorado. Species that show promise in the nursery are further tested under field conditions in order to select the ones most suitable for seeding deteriorated ranges or rehabilitating wildlife habitat.

tundra range north of the arctic circle and its alarming buildup in the food chain to the Alaskan Indians who depend on caribou for 90 percent of their food and most of their clothing. Study of situations such as this must embrace disciplines unknown in the past.

\section{Range Improvement Research}

RANGE SEEDING. Aside from fencing and water development, the first direct range improvement measure that comes to mind is range seeding and Westernwide this is a big problem with some 80 million acres that cannot be improved in a practical length of time by grazing management.

We have made a lot of progress through research (Figure 2) in how to successfully seed by using adapted species, eliminating competition from unwanted species, seeding at the optimum season and depth, and through developing equipment for doing the job. So many people have made contributions that I cannot start to name them.

We have yet to learn why seedings fail on some sites and 
improved by burning or other treatments.

Dramatic progress has been made in the last 20 years in the biological control of noxious range plants, such as the work of Huffaker and Holloway that resulted in effective and practical control by insects of St. Johnswort or Klamath weed in the Pacific Coast States. But in some places this has created new problems since the plant is being replaced by other undesirable species, especially where control is not followed by good management.

The fields of range entomology and plant pathology offer challenges for the future. But the range manager must be patient with the scientist and not expect quick results. In the case of St. Johnswort it took over 30 years of basic research on insects, beginning with work in Australia, to find an effective means of control. In the case of livestock pests, the destructive screwworm for example took some 25 years before the research paid off. And now we find that in Florida deer are making marked population increases because of contol of the screw-worm fly. So far this has been an unexpected side benefit, but it may eventually call for unexpected problems to be solved by the wildlife biologist.

\section{Range Economics}

Underlying the practicality of any range management system and improvement measure is the matter of economics. In this area, research has been limited and we urgently need more studies dealing with costs and returns. Also needed are broader studies of the range economy. Many changes are taking place in range livestock production such as trends to larger, more efficient operations, increased use of supplements, artificial insemination, and mechanization. All have a bearing on range research needs.

\section{Concluding Remarks}

In conclusion, let me attempt to tie together the several threads I have tried to weave into this paper on challenges for future range research.

1. We have urgent need for increased basic research in the physiology and ecology of range plants and range plant communities. This research will be aided by improved research methods and techniques. For example, much progress has been made in electronic data processing, and this should step up all phases of range research including that on the grazing animal. We can expect further development of instruments such as the neutron probe for quick determination of soil moisture. Similarly, we can and must develop better equipment and methodology for rapid and accurate measurement of both biotic and physical characteristics of the range ecosystem.

2. The complex ecosystem we are dealing with will require team work of many disciplines and even new as yet largely unrecognized disciplines such as radio ecology. Perhaps at some future meeting of this Society we could well have a symposium of papers from such disciplines. 3. Despite the proposed emphasis on basic research, we must not lose sight of the continued importance of applied studies, which furnish the immediate guides for management practices. 4. I have stressed the need for a national inventory of range resources. Coupled with this is the need for an inventory of range research currently underway for coordination and effective planning of future research.

I would like to close on a quotation from a paper by the Chairman of the Atomic Energy Commission, Dr. Glen T. Seaborg - On The Creative Scientist His Training and His Role:

"Creative research calls for a combination of qualities only one of which is superior intelligence. It is difficult to specify the combination of characteristics which may be of crucial importance for success in solving a specified scientific problem . . . . Maybe it's just plain hard work, because, without downright hard work, there can be no success in a scientific career. All the productive scientists have been 'smart' it is true, but the ways in which they have been 'smart' have differed greatly. And, they are all dedicated hard workers."

Certainly, we have had many of these dedicated people guiding our past range research, and certainly there are many now with us who will be able to meet the research challenges of the future. 